\title{
Preparation of $\gamma$-Mercaptopropyltrimethoxysilane's Films to Protect Steel Against Corrosion
}

\author{
Cecilia Deyá
}

(Submitted August 21, 2014; in revised form December 11, 2014; published online January 21, 2015)

\begin{abstract}
Traditionally, chromates and phosphates were used as pretreatments for metals to protect them from corrosion during a temporary period. Nowadays, due to their toxicity, replacements are being study. The most studied compounds are based on silanes and, among them, glicidoxypropyltrimethoxysilane, aminopropyltrimethoxysilane, and mercaptopropyltrimethoxysilane are the most important ones. The objective of this research work was to study the anticorrosive protection afforded by films of $\gamma$-mercaptopropyltrimethoxysilane deposited on SAE 1010 steel in order to select the optimum preparation conditions. The films were applied on sandblasted steel after 24 or $48 \mathrm{~h}$ of hydrolysis of the silane in a water/methanol solution $\left(1.5 / 1\right.$, by volume) and cured for $10 \mathrm{~min}$ at $80^{\circ} \mathrm{C}$ or for $1 \mathrm{~h}$ at $100{ }^{\circ} \mathrm{C}$. In order to evaluate the characteristics of the films, Fourier transformed infrared spectroscopy was done on the films and the coated surfaces were observed by scanning electron microscopy. The anticorrosive protection afforded by the films was studied by electrochemical tests employing polarization curves (Tafel mode) in $0.5 \mathrm{M} \mathrm{NaCl}$ solution and corrosion potential measurements in $\mathrm{NaCl} 0.05 \mathrm{M}$. The best results were obtained with silane hydrolyzed for $48 \mathrm{~h}$ cured at $80^{\circ} \mathrm{C}$ for $10 \mathrm{~min}$.
\end{abstract}

Keywords coatings and paints, corrosion and wear, electron microscopy, steel

\section{Introduction}

Pretreatments for metals are used in order to protect them from the action of the aggressive environment during a temporary period (Ref 1-6). Traditionally, chromates and phosphates were used to achieve this goal, but nowadays and due to the toxicity of $\mathrm{Cr}(\mathrm{VI})$ compounds and the eutrophication that phosphate causes (Ref 7,8), their replacements are studied.

Silanes have the general formula $\mathrm{R}^{\prime}-\mathrm{Si}-(\mathrm{RO})_{3}$, being $\mathrm{R}^{\prime}$ a hydrocarbon chain, functionalized or not, and $\mathrm{RO}$ an ethoxy o methoxy group, easily hydrolysable. These silanes interact with the metal forming Si-O-Metal covalent bonds by the reaction between the hydrolysis products of RO groups (silanols) and the oxyhydroxides present on the metal (Fig. 1). These bonds, being covalent, are very strong. Moreover, the silanol groups present in one molecule can react with similar groups in other molecule forming $\mathrm{Si}-\mathrm{O}-\mathrm{Si}$ bonds, which stabilize the film by crosslinking.

The characteristics of the film formed on the metal and the protection afforded to the substrate depend on several variables such as $\mathrm{pH}$ of hydrolysis solvent, time of the silane hydrolysis, addition of additives and/or dopants, way of application, time, and curing temperature of the film. As an example, the amount of RO groups hydrolyzed and capable to react with the metal surface will depend on the time of the silane hydrolysis and on the $\mathrm{pH}$ of the hydrolysis solution (Ref 9-13). Moreover, the

Cecilia Deyá, CIDEPINT, CONICET, UNLP, Calle 52 entre 121 y 122, B1900AYB La Plata, Argentina. Contact e-mail: estelectro2@ cidepint.gov.ar. thickness of the film could vary depending on the number of applications of the silane solution on the metal (Ref 13).

Compounds such as $\gamma$-aminopropyltrimethoxysilane $\left(\mathrm{NH}_{2}\right.$ $\left.\left(\mathrm{CH}_{2}\right)_{3} \mathrm{Si}\left(\mathrm{OCH}_{3}\right)_{3}\right)$ and glycidoxypropyltrimethoxysilane $\left(\mathrm{CH}_{2}\right.$ $\left.\mathrm{OCH}\left(\mathrm{CH}_{2}\right)_{3} \mathrm{Si}\left(\mathrm{OCH}_{3}\right)_{3}\right)$ were studied on several substrates with encouraging results (Ref 14-19); however, on cold-rolled and low-carbon steels, better results were obtained with bis-silanes, $\mathrm{R}_{3} \mathrm{Si}\left(\mathrm{CH}_{2}\right)_{n} \mathrm{R}^{\prime}\left(\mathrm{CH}_{2}\right)_{n} \mathrm{SiR}_{3}$ (Ref 15, 16). On the other hand, $\gamma$-mercaptopropyltrimethoxysilane $\left(\mathrm{HS}\left(\mathrm{CH}_{2}\right)_{3} \mathrm{Si}\left(\mathrm{OCH}_{3}\right)_{3}\right)$ was studied on hot deep or electro-galvanized steels with good results (Ref 3, 20-22).

The objective of this research work was to study the anticorrosive protection afforded by $\gamma$-mercaptopropyltrimethoxysilane (MTMO) films applied on sandblasted SAE 1010 steel in order to select the better film-forming conditions. The variables under study were time of silane hydrolysis, curing conditions (time and temperature), and number of applications. The films formed on the metal were observed by Scanning Electron Microscopy (SEM) and characterized by energy dispersive $\mathrm{x}$-ray analysis (EDX). The protective properties of the films were studied by polarization curves and corrosion potential measurements.

\section{Experimental Procedure}

Silane suspension was prepared dissolving $1.3 \mathrm{~mL}$ of MTMO in $1.9 \mathrm{~mL}$ of methanol/water solution $(1.5 / 1$, by volume). The $\mathrm{pH}$ of the water/methanol solution was previously adjusted to 4 with acetic acid. The suspension was stirred for 24 or $48 \mathrm{~h}$ in order to get the desired hydrolysis degree. A sample of these solutions was applied on glass and allowed to dry at room temperature. The dried films were removed by spatula from the glass, and Fourier Transform Infrared (FTIR) spectra were obtained using a Perkin Elmer Spectrum One spectrometer. The spectra were obtained as an average of 10 
scans with a resolution of $1 \mathrm{~cm}^{-1}$ in the range of 650$4000 \mathrm{~cm}^{-1}$. The spectra could not be done directly on the solutions due to water interference.

After hydrolysis, $28.4 \mathrm{~mL}$ of the same methanol/water solution was added to the hydrolyzed silane. The final concentration of MTMO was $4 \%$, by volume (Ref 20 ). Two additives were also added, one in order to avoid flash rusting of the steel while the film is curing, SER AD FA 179 (Ref 23), and the other a wetting agent, TEGO 650 (Ref 24), 0.5 and $0.01 \%$, by weight, respectively. SAE 1010 $2.5 \times 7.0 \mathrm{~cm}^{2}$ steel panels, sandblasted until Sa $21 / 2$ degree (SIS 055900 ), with an average roughness Rt $\sim 21 \mu \mathrm{m}$ (being Rt the sum of the height of the highest peak and the depth of the lowest valley within the measured length) were immersed in the solution for $1 \mathrm{~min}$. After removal, at $32 \mathrm{~cm} / \mathrm{min}$, a set of samples was cured for $1 \mathrm{~h}$ at $100 \pm 2{ }^{\circ} \mathrm{C}$ and another set at $80 \pm 2{ }^{\circ} \mathrm{C}$ for $10 \mathrm{~min}$ in oven (Ref 9, 19). The procedure (immersion-curing) was repeated 2 or 3 times, in order to get different numbers of silane layers. In Table 1, a detail of the pretreatment variables is shown.

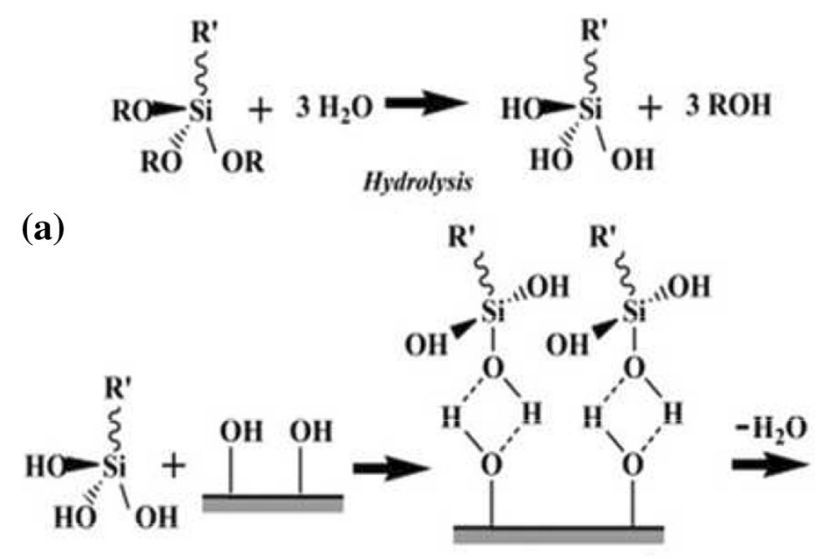

(b) Hydrogen-bonded adsorption

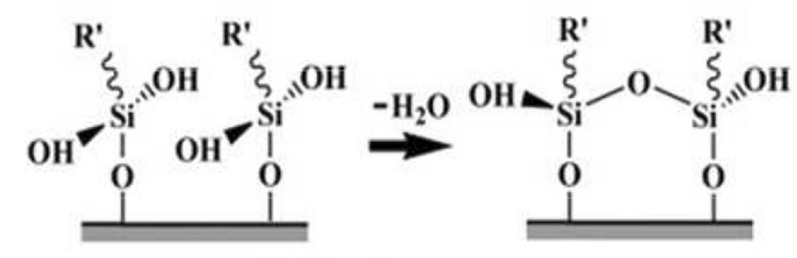

(c)

Condensation

Fig. 1 Scheme of the silanes reaction (a) hydrolysis, (b) adsorption on the metal, (c) condensation
No flash rusting was observed on the cured samples.

In order to characterize the cured films and to determine the functional groups present on then, FTIR spectra were obtained. The silane solution was applied on glass and cured at the different conditions. The cured films were removed from the glass, by spatula, and the FTIR obtained under the same conditions as the dried films.

The films applied on steel were observed by SEM, and their composition was determined by EDX. A Phillips SEM 505 coupled with an EDAX Ox Prime 10 (Energy dispersed form) was used; the EDX device was calibrated with a $\mathrm{Zn}(30 \%)-\mathrm{Cu}$ (70\%) alloy for both gain and peak position.

The anticorrosive protection behavior was studied by means of electrochemical tests such as polarization curves and corrosion potential measurements. Polarization curves, Tafel mode, were carried out employing the typical three-electrode cell after $2 \mathrm{~h}$ of immersion in $\mathrm{NaCl} 0.5 \mathrm{M}$. A saturated calomel electrode (SCE) was used as reference electrode; a platinum grid was employed as counter electrode and the coated steel as working electrode. The swept amplitude was $\pm 0.25 \mathrm{~V}$ from the corrosion potential; the scan rate was $0.5 \mathrm{mV} / \mathrm{s}$ and the scan increment $1 \mathrm{mV}$. The measurements were done employing a potentiostat/galvanostat PAR $273 \mathrm{~A}$. The data obtained were processed with the corrosion Software M352 from EG\&G Princeton Applied Research. The exposed area was $0.42 \mathrm{~cm}^{2}$, delimited by bee wax. Similar determination was done on naked sandblasted steel, as blank.

Corrosion potential measurements were done on pretreated and on naked sandblasted steel immersed in $0.05 \mathrm{M} \mathrm{NaCl}$ employing a SCE. The area exposed was $1.6 \mathrm{~cm}^{2}$, delimited by bee wax. Measurements were done for $4 \mathrm{~h}$.

\section{Results and Discussion}

\subsection{Characterizations of the Silane Solutions}

The FTIR spectra of the solution samples dried at room temperature can be seen in Fig. 2. These spectra showed the differences of the solutions related to the presence of silane and silanols. Peaks due to silane $\left(\mathrm{Si}-\mathrm{O}-\mathrm{CH}_{3}\right.$ bonds at 1190 and $1089 \mathrm{~cm}^{-1}$ and $\mathrm{CH}$ bonds at 2836 and $2942 \mathrm{~cm}^{-1}$ ) diminished their intensity as hydrolysis time elapsed. Moreover, peaks due to the $\mathrm{OH}$ groups present in silanol and due to SiOSi bonds (3380 and $1041 \mathrm{~cm}^{-1}$, respectively) increased their intensity (Ref 14). The increased amount of $\mathrm{SiOH}$ groups in the silane solution might produce better protective films, as the interaction undergoes between the $\mathrm{SiOH}$ and the oxyhydroxides present on metal surface and the higher amount of $\mathrm{SiOH}$, more interactions, and more possibilities to form covalent

Table 1 Variables of the applied pretreatments and corrosion rate, from polarization curves in $\mathrm{NaCl} 0.5 \mathrm{M}$

\begin{tabular}{|c|c|c|c|c|}
\hline Pretreatment & Time of hydrolysis, $h$ & Curing conditions & Number of applications & Corrosión rate, $\mu \mathrm{A} / \mathrm{cm}^{2}$ \\
\hline $\mathrm{X} 2$ & 24 & $100^{\circ} \mathrm{C}, 60 \mathrm{~min}$ & 2 & 15.2 \\
\hline X3 & 24 & $100^{\circ} \mathrm{C}, 60 \mathrm{~min}$ & 3 & 7.1 \\
\hline $\mathrm{Z} 2$ & 24 & $80{ }^{\circ} \mathrm{C}, 10 \mathrm{~min}$ & 2 & 199.4 \\
\hline $\mathrm{Z3}$ & 24 & $80^{\circ} \mathrm{C}, 10 \mathrm{~min}$ & 3 & 73.0 \\
\hline $\mathrm{C} 2$ & 48 & $100^{\circ} \mathrm{C}, 60 \mathrm{~min}$ & 2 & 101.0 \\
\hline $\mathrm{C} 3$ & 48 & $100^{\circ} \mathrm{C}, 60 \mathrm{~min}$ & 3 & 3.7 \\
\hline $\mathrm{F} 2$ & 48 & $80^{\circ} \mathrm{C}, 10 \mathrm{~min}$ & 2 & 28.3 \\
\hline F3 & 48 & $80^{\circ} \mathrm{C}, 10 \mathrm{~min}$ & 3 & 5.2 \\
\hline
\end{tabular}


bonds (Ref 15, 16). On the other hand, the increase in the amount of SiOSi indicates some degree of crosslinking.

The thiol group is characterized by a weak and difficult-toobserve band at $2568 \mathrm{~cm}^{-1}(\operatorname{Ref} 25)$.

\subsection{Characterization of the Films}

The FTIR spectra of the different cured films (Fig. 3) showed that after curing, the organic groups present on the films are similar, despite the hydrolysis time of the MTMO and the curing conditions. The bands at 1113 and $1041 \mathrm{~cm}^{-1}$, corresponding to Si-O-Si bonds, were more clearly defined than on the dried films indicating a more important degree of

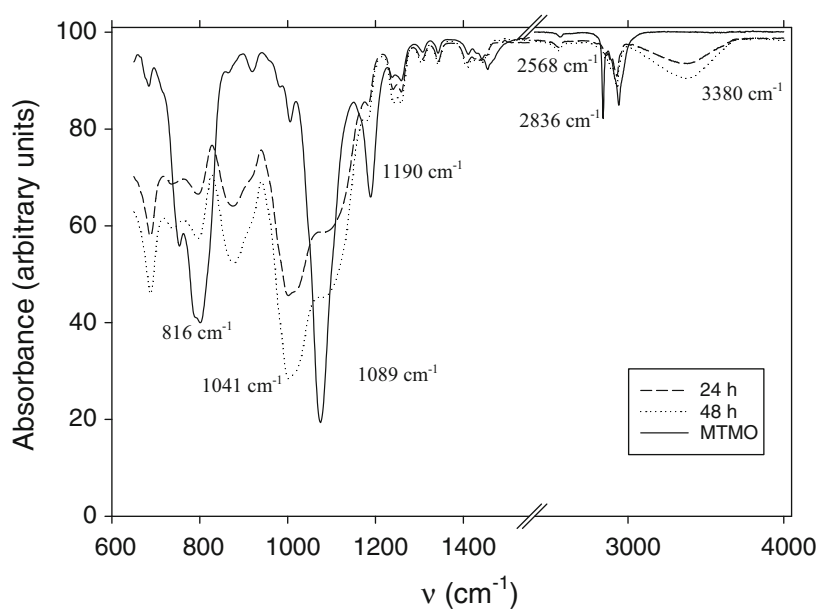

Fig. 2 FTIR spectra of the dried films and of pure MTMO

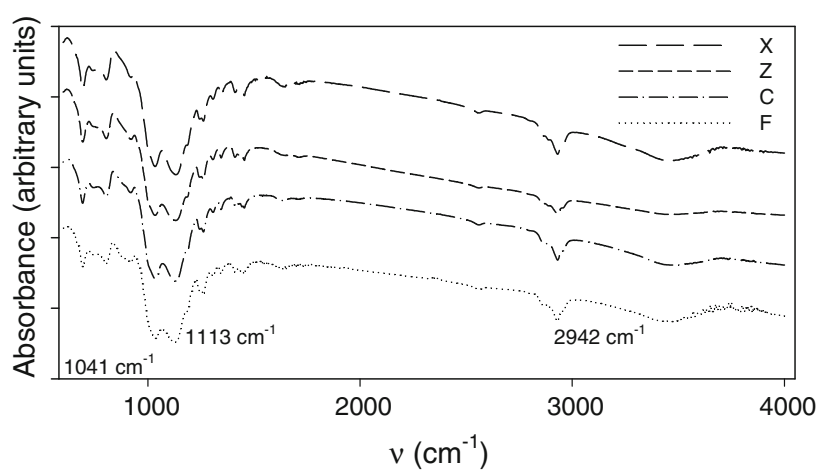

Fig. 3 FTIR spectra of the cured films crosslinking (Ref 14). Moreover, the loss of intensity in peaks 2836 and $2942 \mathrm{~cm}^{-1}$ would indicate a partial loss of $\mathrm{CH}$ chain. This loss might occur together with the thiol group. These results were later confirmed by EDX analysis.

The cured films were observed by SEM. The steel substrate might be covered in different ways, depending on the roughness of the surface and on the thickness of the film:

1. The surface might not be completely covered by the silane leaving the peaks without protection (Fig. 4a); in this case, pools of silane might appear.

2. The surface might be completely covered. In this case, several possibilities may occur: a thin film follows the roughness of the surface, covering peaks and valleys, and the thickness of the film is homogenous (Fig. 4b); a thick film, with different thickness, covers peaks and valleys (Fig. 4c) and a film that follows the roughness of the metal but it is thicker in valleys, forming pools (Fig. 4d). Figure 4(e) shows a representation of the naked steel.

Figure 5(a) corresponds to the steel surface after pretreatments X2, while Table 2 shows the composition of the film. No cracks or holes appeared, even when they are seen with higher magnification (Fig. 5b). The film followed the substrate roughness (Fig. 4b). The same film structure with similar composition was observed in the case of pretreatment $\mathrm{Z} 2$ (Fig. 5c; Table 2). As can be seen, no important differences appeared in the composition (Table 2) or in the structure of the films, despite the different curing conditions.

The detection of iron is related with the penetration degree of the electron beam (as the only source of Fe is the substrate metal), so the amount of this element could be related with the thickness of the film. Taking this into account, it can be said that the thickness of the films was similar.

The crosslinking degree is difficult to be determined by EDX measurements as a higher amount of $\mathrm{O}$, from the oxyhydroxides on steel, might be detected. However, as the theoretical ratio $\mathrm{C} / \mathrm{Si} / \mathrm{O}$, for non-polymerized MTMO, is $6 / 1 / 3$, polymerization occurred on steel as less $\mathrm{C}$ and $\mathrm{O}$, related to $\mathrm{Si}$, appeared in the cured films (Table 2). In the case of X2, the ratio $\mathrm{C} / \mathrm{Si} / \mathrm{O}$ was $1.2 / 1.0 / 0.95$, similar to $\mathrm{Z} 2$. Moreover, some $\mathrm{S}$ was lost, in the case of $\mathrm{X} 2$ as the ratio $\mathrm{S} / \mathrm{Si}$ was $\sim 0.7 / 1.0$, while the theoretical ratio is $1.0 / 1.0$. In the case of $\mathrm{Z} 2$, the ratio $\mathrm{S} / \mathrm{Si}$ was almost the theoretical one indicating that the milder curing conditions produce less S loss. The loss of $\mathrm{S}$ atoms also occurred in the case of MTMO applied on hot deep galvanized steel and cured $30 \mathrm{~min}$ at $120{ }^{\circ} \mathrm{C}$ in which the ratio $\mathrm{S} / \mathrm{Si}$ was around 0.8/1.0 (Ref 20).

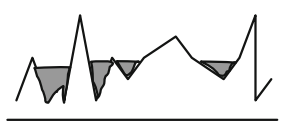

(a)

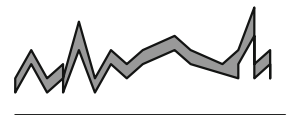

(b)

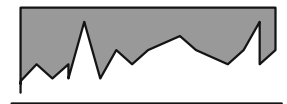

(c)

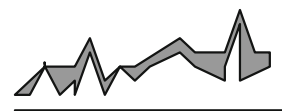

(d)

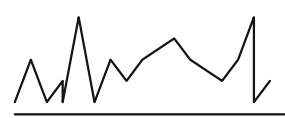

(e)

Fig. 4 Schematic representation of the sandblasted steel, (a) peaks are left without protection, (b) the silane film has homogenous thickness, it follows the roughness profile, (c) a thicker film, with different thickness, (d) a thin film with pools, and (e) naked steel 


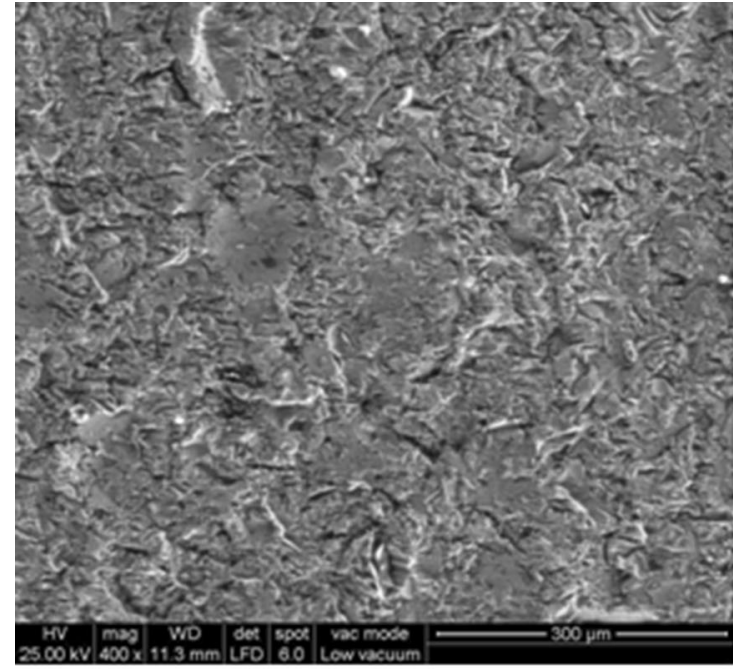

(a)

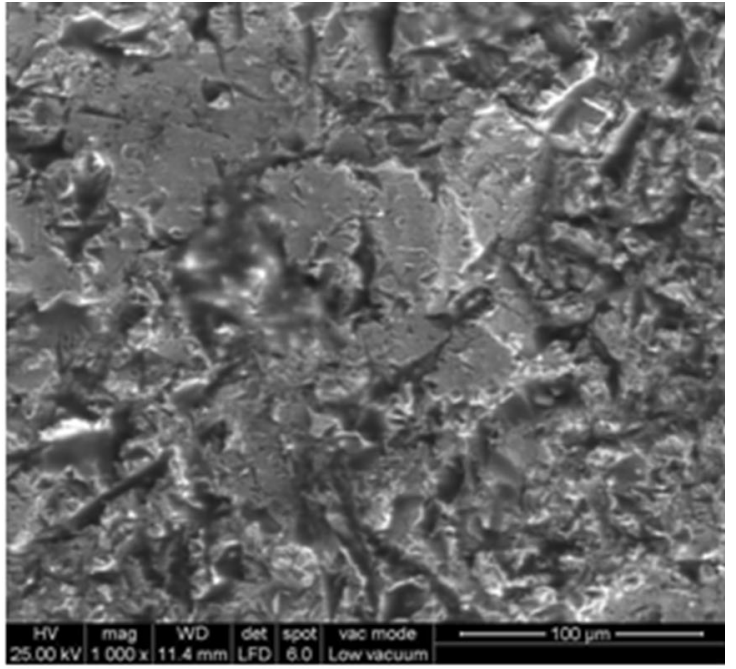

(b)

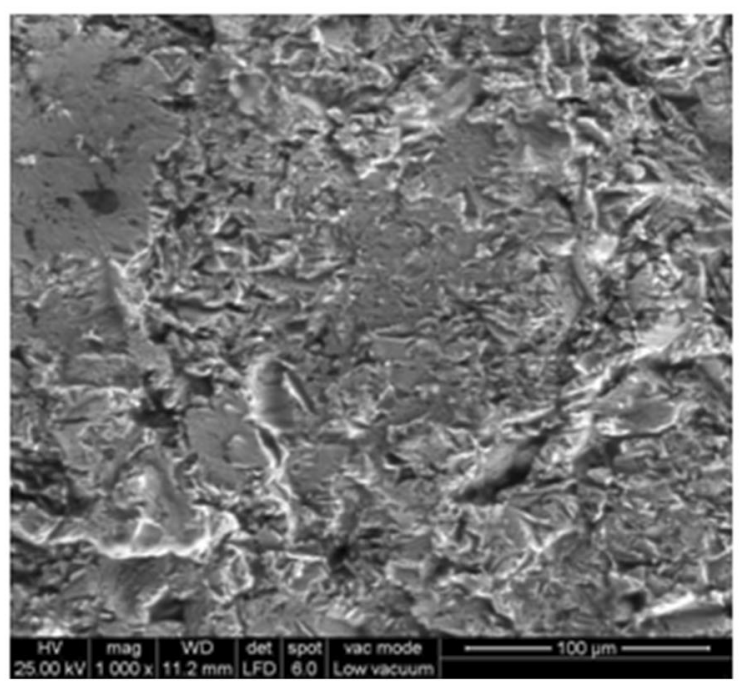

(c)

Fig. 5 SEM photograph of the silane film on steel. (a) X2 $(400 \times)$, (b) X2 $(1000 \times)$, (c) Z2 $(1000 \times)$

Table 2 Composition of the cured films on steel

\begin{tabular}{lcccccc}
\hline & \multicolumn{3}{c}{ \% by atom } & & \\
\cline { 2 - 5 } Pretreatment & $\mathbf{C}$ & $\mathbf{O}$ & $\mathbf{S i}$ & $\mathbf{S}$ & Fe & C/O/Si ratio \\
\hline X2 & 26 & 20 & 21 & 15 & 18 & $1.2 / 0.95 / 1.0$ \\
Z2 & 19 & 17 & 21 & 20 & 23 & $0.9 / 0.85 / 1.0$ \\
C2 & & & & & & $0.7 / 1.0$ \\
Valley & 36 & 27 & 19 & 18 & 0 & $1.9 / 1.4 / 1.0$ \\
Peak & 22 & 19 & 15 & 6 & 38 & $1.5 / 1.3 / 1.0$ \\
\hline
\end{tabular}

These results confirm the results obtained by FTIR spectra. On the other hand, on the surface of samples prepared with 48h hydrolyzed MTMO, pools of silane appeared (Fig. 6). In Fig. 6(a), SEM photograph of sample $\mathrm{C} 2$, accumulation of silane on the valleys of the surface, can be seen. The composition of these films can be seen in Table 2. The differences on the amount of iron showed that the thickness of the film was higher on the valleys than on the peaks, while the difference on the amount of sulfur indicated a difference on film composition. In the first case, the ratio $\mathrm{S} / \mathrm{Si}$ was $0.95 / 1.0$, near the theoretical ratio, while in the last case, $0.4 / 1.0$, indicating a higher loss in the peaks as the area was more exposed. This morphology of the silane film also occurred in the case of sample F2 (Fig. 6b). A scheme of these situations can be seen in Fig. 4(d).

The ratio $\mathrm{C} / \mathrm{Si} / \mathrm{O}$ was different on the valleys than on the peaks indicating the loss of more $\mathrm{C}$ in the last case. This can be due to the loss of the propyl-chain, together with the S, or due to crosslinking. 
In the case of the samples immersed three times, in every case, the amount of silane was higher in the valleys than on the peaks, and pools of silane can be easily seen (Fig. 7a and b). As in the case of two immersions, the ratio $\mathrm{C} / \mathrm{Si} / \mathrm{O} / \mathrm{S}$ indicated that crosslinking might occur and that some $\mathrm{S}$ atoms were lost.

The polarization curves (Fig. 8a and b), Tafel mode, showed that all the pretreatments diminished the anodic current, probably due to an increase in the $\mathrm{SiO}$ metal bonds formed while curing that isolated the substrate and diminished the anodic active sites (Ref 16). However, in the case of the 2immersion pretreatments, only X2 and F2 diminished the cathodic current in approximately one order of magnitude. In the case of the 3-immersion pretreatments, all of them diminished the cathodic current, due to an increase in the silane-metal interactions during film-forming process and a higher degree of crosslinking (Ref 16). The most important effect was afforded by pretreatment $\mathrm{C} 3$ as the diminishing was almost of 2 orders of magnitude. Similar results were obtained, on steel, by Asadi et al. employing a mixture of silanes (Ref 19) and by Van Schaftinghen et al. employing bis-silanes (Ref 16).

In Table 1, the values of the corrosion current, calculated from Tafel plot, can be seen. These values showed that the lower corrosion current was obtained with the 3-immersion pretreatments. This could be related with the morphology of the films, as more silane was deposited in these pretreatments and a denser crosslinking film could be obtained (Ref 16, 21).

In Fig. 9, the corrosion potential values can be seen. All the pretreatments depleted the corrosion potential to more positive values, approximately $150 \mathrm{mV}$. Besides, it can be seen that the steel without pretreatment reached the value of $-610 \mathrm{mV}$ after 90 min of immersion, while the pretreated steel samples did not reach that value along the test. It is important to remark that the corrosion potential of steel protected with pretreatment F3 diminished constantly reaching the value $-552 \mathrm{mV}$ at the end of the test. This value was the most negative one among the pretreated samples.

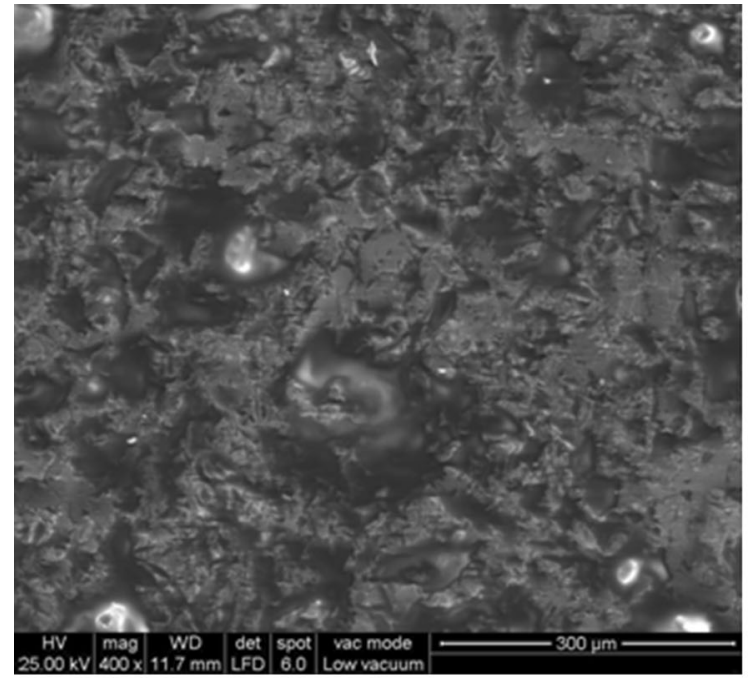

(a)

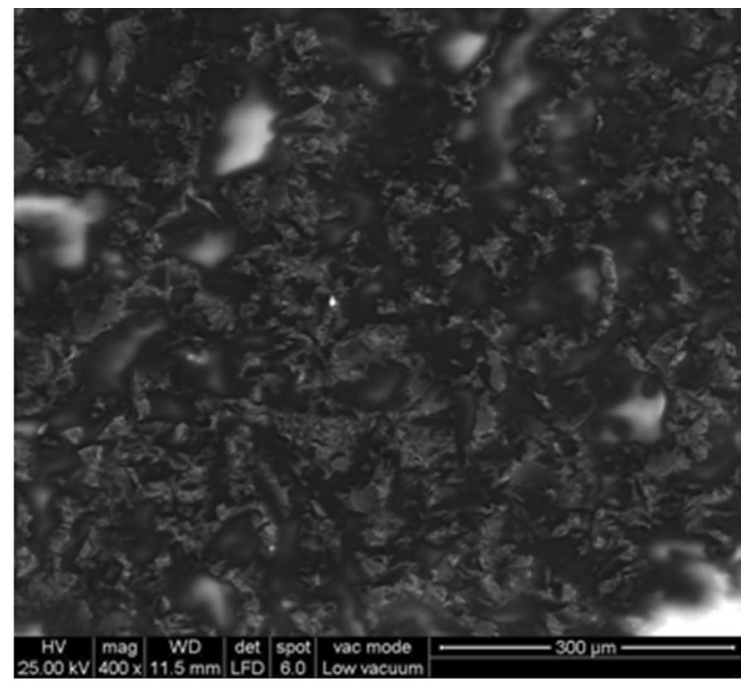

(b)

Fig. 6 SEM photograph of the silane film on steel $(400 \times)$. (a) C2 and (b) F2 pretreatments

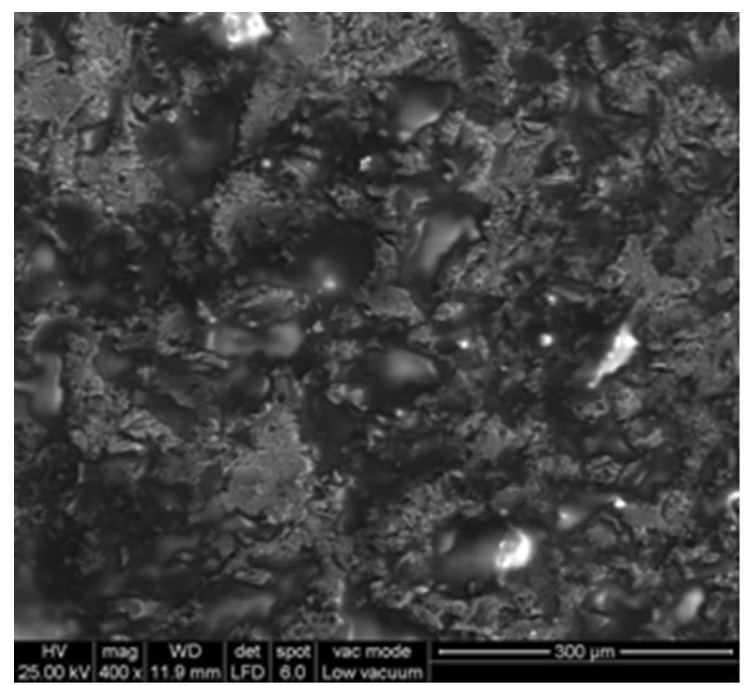

(a)

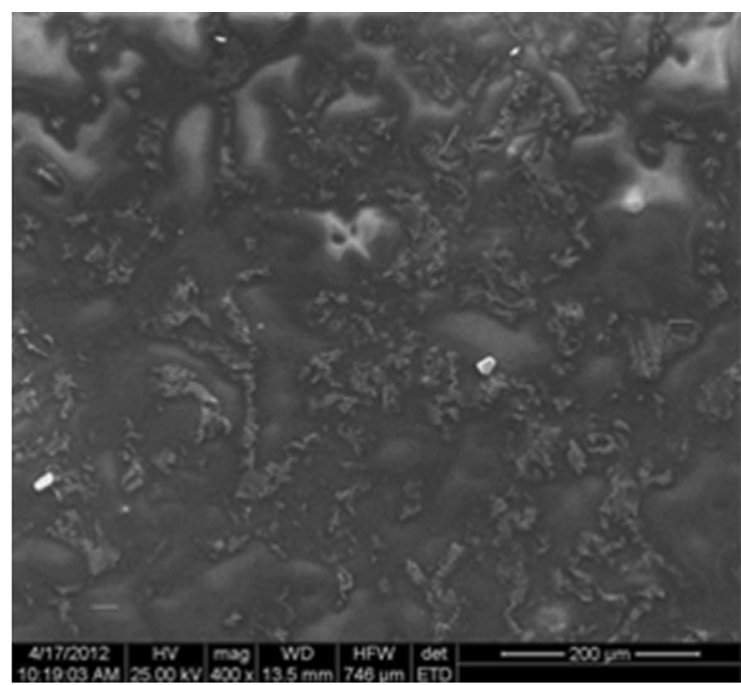

(b)

Fig. 7 SEM photograph of the silane film on steel $(400 \times)$. (a) X3 and (b) F3 


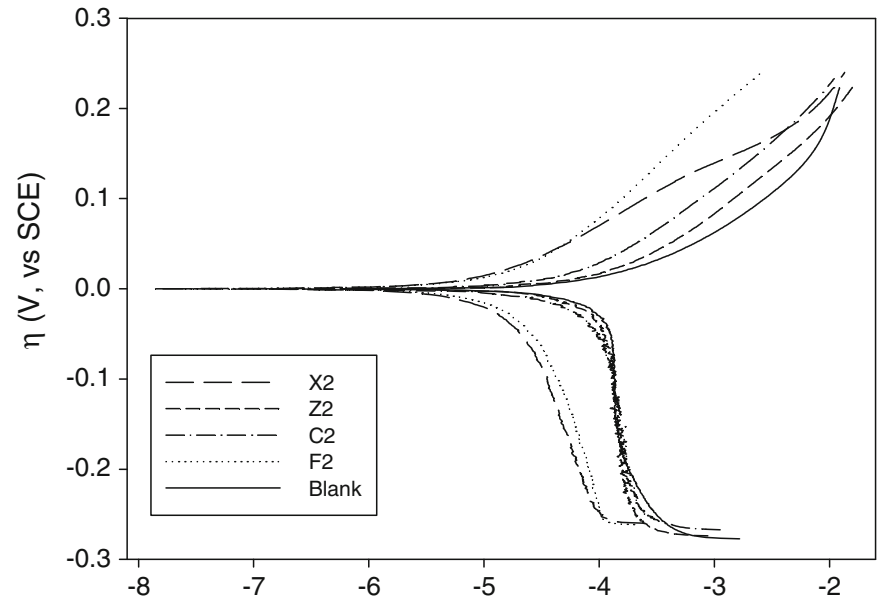

(a)

$\log \mathrm{J}\left(\mu \mathrm{A} \cdot \mathrm{cm}^{-2}\right)$

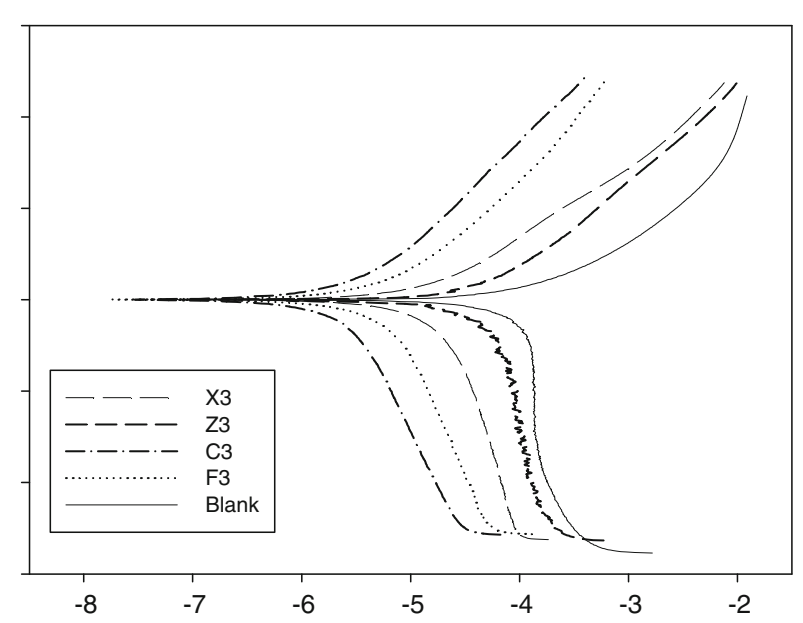

(b)

$\log \mathrm{J}\left(\mu \mathrm{A} \cdot \mathrm{cm}^{-2}\right)$

Fig. 8 Polarization curves (Tafel mode) of the samples after $2 \mathrm{~h}$ in $\mathrm{NaCl} 0.5 \mathrm{M}$. (a) 2-immersion pretreatment and (b) 3-immersion pretreatment

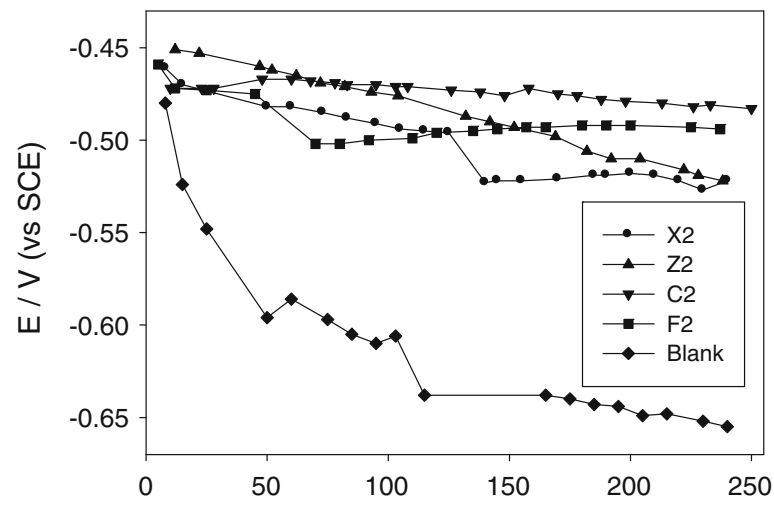

(a)

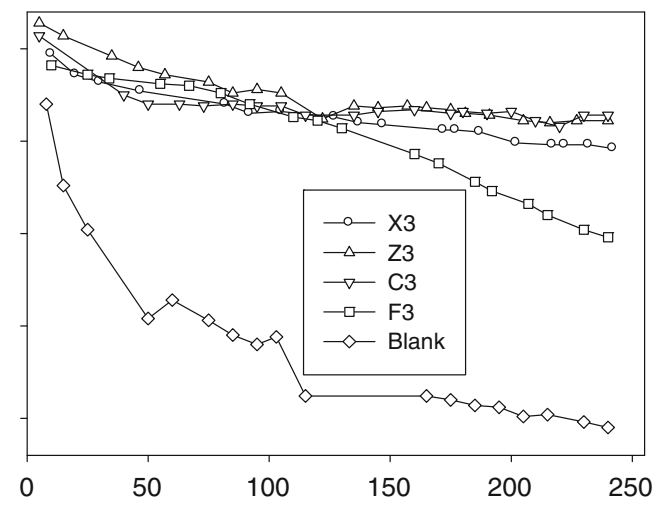

(b)

Time / min

Fig. 9 Evolution of the corrosion potential of the samples immersed in $\mathrm{NaCl} 0.05 \mathrm{M}$. (a) 2-immersion pretreatment and (b) 3 -immersion pretreatment
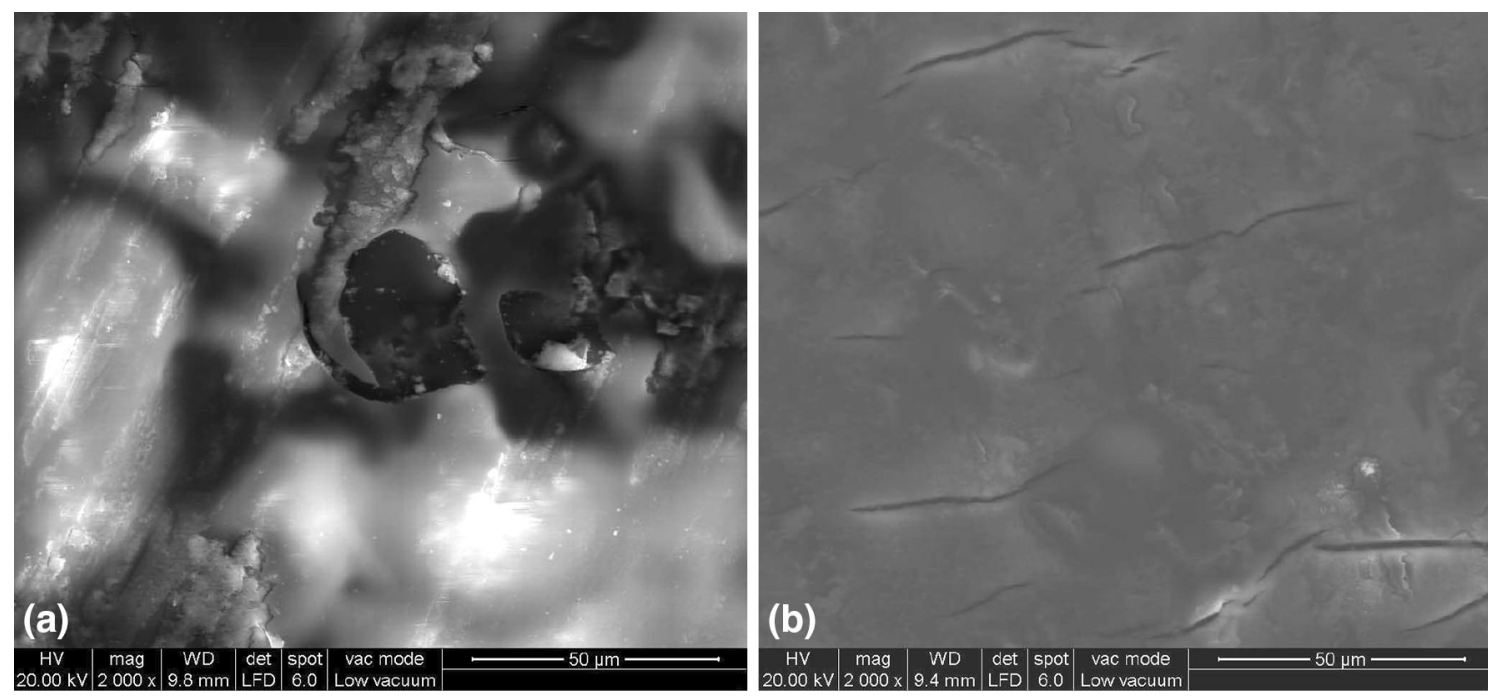

Fig. 10 SEM photograph of the silane film on steel after $24 \mathrm{~h}$ of immersion in $\mathrm{NaCl} 0.05 \mathrm{M}(2000 \times)$. (a) $\mathrm{C} 3$ and (b) $\mathrm{F} 2$ pretreatments 
As the films composition determined by FTIR (on dried film applied on glass) and by EDS (done on the steel) were similar, the most important factor for the different protective behaviors seemed to be the interaction between the metal and the silanol. When more silanol groups were present in the hydrolysis solution (longer hydrolysis time), the interaction between these groups and the oxyhydroxides on the metal was easier, and a good protective film was formed at lower temperature and shorter curing times. Stronger curing conditions affect the protective properties of the film, probably it made the film more permeable, as no pore or cracks could be seen by SEM, but the anticorrosive performance was poor.

When less $\mathrm{SiOH}$ groups were present in the silanol, higher temperature and longer time were necessary to achieve good interaction between the silanol and the oxyhydroxides on the metal surface. In this case, curing at $100{ }^{\circ} \mathrm{C}$ for $1 \mathrm{~h}$ gave better protective properties.

When samples F2 and C3, two of the ones with better protective performance, were observed by SEM after the exposition to $\mathrm{NaCl} 0.05 \mathrm{M}$ for $24 \mathrm{~h}$, the partially detachment of the silane film could be seen (Fig. 10a and b). In the case of F2, the silane film presented cracks (54 $\mathrm{m}$ long and $3 \mu \mathrm{m}$ wide), but the roughness of the substrate cannot be seen. In the case of C3, the films seemed to cover the whole steel surface with some holes of $\sim 30 \mu \mathrm{m}$. Bellow these holes, other layer of the silane film seemed to be present. No iron oxides could be seen.

\section{Conclusions}

In agreement with the results obtained in this research work, it is possible to protect steel by the formation of a $\gamma$ mercaptopropyltrimethoxysilane film on its surface. The chemical composition of the films formed on sandblasted steel and their morphology are independent of the hydrolysis time of the silane solution and on the curing conditions.

The best anticorrosive behavior of the pretreatment was achieved by the 3-immersion pretreatments, probably due the repetition of the cycles silane application-curing was enough to cover the valleys and peaks of the metal surface, obtaining a thicker film. The time of hydrolysis and the curing conditions are also factors to be taken into account in order to get a good protection. The films obtained after $48 \mathrm{~h}$ of hydrolysis protected the steel better if they were cured at $80{ }^{\circ} \mathrm{C}$ for $10 \mathrm{~min}$ while the better protection of the steel by the films obtained after $24 \mathrm{~h}$ of hydrolysis was brought when they were cured for $1 \mathrm{~h}$ at $100{ }^{\circ} \mathrm{C}$.

\section{Acknowledgments}

The author thanked to Consejo Nacional de Investigaciones Científicas y Técnicas (CONICET), Universidad Nacional de La Plata (UNLP) and Comisión de Investigaciones Científicas of Buenos Aires (CICPBA), for the economical support to do this research and to Bernardo Browne and Andrés Campbell from CAMSi-X for the silane.

\section{References}

1. W.J. van Ooij, D. Zhu, M. Stacy, A. Seth, T. Mugada, J. Gandhi, and P. Puomi, Corrosion Protection Properties of Organofunctional Silanes-An Overview, Tsinghua Sci Technol, 2005, 10(6), p 639-664
2. A.M. Cabral, R.G. Duarte, M.F. Montemor, and M.G.S. Ferreira, A Comparative Study on the Corrosion Resistance of AA2024-T3 Substrates Pre-treated with Different Silane Solutions. Composition of the Films Formed, Prog. Org. Coat., 2005, 54, p 322-331

3. P.R. Seré, C. Deyá, W.A. Egli, C.I. Elsner, and A.R. Di Sarli, Protection of Galvanized Steel with Silanes: Its Comparison with Chromium(VI), J. Mater. Eng. Perform., 2014, 23(1), p 342-348

4. L. Wang, C. Liu, H. Yu, and C. An, Structure and Corrosion Resistance of a Composite $\gamma$-Amino Propyl Triethoxy Silane and $\gamma$-Glycidoxy Propyl Trimethoxy Silane Conversion Coating on Galvanized Steel, J. Iron. Steel Res. Int., 2012, 19(11), p 46-51

5. H. Kim, J. Zhang, R. Yoon, and R. Gandour, Development of Environmentally Friendly Nonchrome Conversion Coating for Electrogalvanized Steel, Surf. Coat. Technol., 2004, 188-189, p 762-767

6. D. Wang and G.P. Bierwagen, Sol-Gel Coatings on Metals for Corrosion Protection, Prog. Org. Coat., 2009, 64, p 327-338

7. E.P. Odum, Ecología, 3rd ed., W. B. Saunders Co, Philadelphia, 1972, p 117-118

8. "Toxicological Profile for Chromium", Agency for Toxic Substances, U.S. Public Health Service, Report No. ASTSDR/TP-88/10, July, 1989

9. M.-A. Chen, X.-B. Lu, Z.-H. Guo, and R. Huang, Influence of Hydrolysis Time on the Structure and Corrosion Protective Performance of (3-Mercaptopropyl)triethoxysilane Film on Copper, Corros. Sci., 2011, 53, p 2793-2802

10. B. Chico, D. de la Fuente, M.L. Pérez, and M. Morcillo, Corrosion Resistance of Steel Treated with Different Silane/Paint Systems, J. Coat. Technol. Res., 2012, 9, p 3-13

11. S.H. Zaferani, M. Peikari, D. Zaarei, I. Danaee, J.M. Fakhraei, and M. Mohammadi, Using Silane Films to Produce an Alternative for Chromate Conversion Coatings, Corrosion, 2013, 69(4), p 372-387

12. J.H. Osborne, K.Y. Blohowiak, S.R. Taylor, C. Hunter, G. Bierwagen, B. Carlson, D. Bernard, and M.S. Donley, Testing and Evaluation of Nonchromated Coating Systems for Aerospace Applications, Prog. Org. Coat., 2001, 41, p 217-225

13. M. Qian, A. Mcintosh Soutar, X.H. Tan, X.T. Zeng, S. L. Wijesinghe, Two Part Epoxy-siloxane Hybrid Corrosion Protection Coating for Carbon Steel. Thin Solid Film , 2009, 517, p 5237-5242

14. L. Yang, J. Feng, W. Zhan, and J. Qu, Film Forming Kinetics and Reaction Mechanism of $\gamma$-Glycidoxypropyltrimethoxysilane on Low Carbon Steel Surfaces, Appl. Surf. Sci., 2010, 256, p 6787-6794

15. B. Chico, J.C. Galván, D. de la Fuente, and M. Morcillo, Electrochemical Impedance Spectroscopy Study of the Effect of Curing Time on the Early Barrier Properties of Silane Systems Applied on Steel Substrates, Prog. Org. Coat., 2007, 60, p 45-53

16. T. van Schaftinghen, C. Le Pen, H. Terryn, and F. Hörzenberger, Investigation of the Barrier Properties of Silanes on Cold Rolled Steel, Electrochim. Acta, 2004, 49, p 2997-3004

17. A.L. Kuan Tan and A. Mcintosh Soutar, Hybrid Sol-Gel Coatings for Corrosion Protection of Copper, Thin Solid Films, 2008, 516, p 5706-5709

18. F. Deflorian, S. Rossi, L. Fedrizzi, and M. Fedel, Integrated Electrochemical Approach for the Investigation of Silane Pre-treatments for Painting Copper, Prog. Org. Coat., 2008, 63, p 338-344

19. N. Asadi, R. Naderi, M. Saremi, S.Y. Arman, M. Fedel, and F. Deflorian, Study of Corrosion Protection of Mild Steel by Eco-Friendly Silane SolGel Coating, J. Sol-Gel. Sci. Technol., 2014, 70(3), p 329-338

20. U. Bexell and T.M. Grehk, A Corrosion Study of Hot-Dip Galvanized Steel Sheet Pre-treated with $\gamma$-Mercaptopropyltrimethoxysilane, Surf. Coat. Technol., 2007, 201, p 4734-4742

21. W.E.G. Hansal, S. Hansal, M. Pflzler, A. Kornherr, G. Zifferer, and G.E. Nauer, Investigation of Polysiloxane Coatings as Corrosion Inhibitors of Zinc Surfaces, Surf. Coat. Technol., 2006, 200, p 3056-3063

22. F. Sinapi, T. Issakova, J. Delhalle, and Z. Mekhalif, Study of (3Mercaptopropyl)trimethoxysilane Reactivity on Zinc: Comparison with Organothiol and Organosilane Thin Films, Thin Solid Films, 2007, 515, p 6833-6843

23. SER AD FA 179 Technical Sheet. http://coatings.specialchem.com/ product-categories/additives-corrosion-inhibitors/t-coatings/c-additivescorrosion-inhibitors-flash-rust-inhibitors

24. TEGO 650 Technical Sheet. http://evonik.tego.de/pdf/daten/engl/ Dispers_650.pdf

25. F. Zucchi, A. Frignani, V. Grassi, G. Trabanelli, and M. DalColle, The Formation of a Protective Layer of 3-Mercapto-propyl-trimethoxysilane on Copper, Corros. Sci., 2007, 49, p 1570-1583 